REVIEW

\title{
Autonomic dysreflexia: a medical emergency
}

\author{
J Bycroft, I S Shergill, E A L Choong, N Arya, P J R Shah
}

Postgrad Med J 2005;81:232-235. doi: 10.1136/pgmj.2004.024463

Autonomic dysreflexia is an important clinical diagnosis that requires prompt treatment to avoid devastating complications. The condition may present itself to all members of medical and surgical specialties, who may not be accustomed to treating it. It is the clinician's responsibility to have a basic understanding of the pathophysiology of the condition and the simple steps required to treat it.

See end of article for authors' affiliations

Correspondence to: Mr I S Shergill, 62 Ward Avenue, Grays, Essex RM17 5RW, UK; super_iqi@hotmail.com

Submitted 27 May 2004 Accepted 21 June 2004
A utonomic dysreflexia $(\mathrm{AD})$ is a condition of uncontrolled sympathetic response secondary to a precipitant, that generally occurs in patients with injury to the spinal cord at levels of $\mathrm{T} 6$ and above. $\mathrm{AD}$ is important on two accounts. Firstly, because of the lack of awareness of the condition among healthcare workers, and secondly because of fatal complications that may ensue in the affected patient. ${ }^{12}$ Simple steps ensure prevention, early recognition, and treatment in patients.

INCIDENCE AND ASSOCIATIONS OF AD

It remains unclear as to how common $\mathrm{AD}$ is among spinal cord injury (SCI) patients, however it is probable that between $50 \%$ and $70 \%$ of patients with lesions at or above T6 experience symptoms of AD. ${ }^{2-4}$ Nevertheless, it has certainly been reported in patients with lesions lower than this. ${ }^{56}$ Patients with both complete and incomplete lesions are affected, however it is thought that symptoms are less common and less severe in the latter group. ${ }^{7}$ While the commonest association of $\mathrm{AD}$ is SCI, it may also result from non-traumatic causes, such as spinal cord tumours $^{8}$ or after neurosurgery above the level of T6. ${ }^{9}$ It may also be secondary to medical conditions such as multiple sclerosis. ${ }^{10} \mathrm{AD}$ may also coexist with other rarer causes of hypertension, for example catecholamine secreting tumours, ${ }^{11}$ which may in turn be solely responsible for symptoms in patients with SCI, falsely presenting as $\mathrm{AD} .{ }^{12}$ While $\mathrm{AD}$ is more common in patients with chronic SCI, those with high and complete lesions may also be at risk during the acute phase of SCI. ${ }^{13}$

\section{PATHOPHYSIOLOGY OF AD}

The most prominent component of an $\mathrm{AD}$ episode is a dramatic rise in blood pressure. Numerous theories have been proposed to explain this phenomenon. ${ }^{2}$ Most of these involve an element of aberrant sympathetic nervous system overactivity. Normal regulation of sympathetic output from the spinal cord is modulated by input from the higher centres; after SCI this input is lost, and spinal circuits alone are responsible for sympathetic activity at and below the lesion level. The acute period after SCI is generally characterised by hypotension and bradycardia. After this period, depending on the level and severity of lesion, exaggerated reflexes are established that can lead to the symptoms of $\mathrm{AD}$. These changes are thought to occur because of synaptic re-organisation, and a reduction in gliosis around the pre-synaptic sympathetic neurones. ${ }^{14}$ The basis for the $\mathrm{AD}$ response seems to be related to an exaggerated reaction of sympathetic pre-ganglionic neurones to afferent stimuli, however the part that spinal interneurones play has yet to be determined..$^{15} 16$ The reason that $\mathrm{AD}$ is a feature of lesions at or above the T6 level is that the splanchnic circulation then becomes involved in this sympathetic overactivity. Because of this "autonomic imbalance", splanchnic and peripheral vasoconstriction, ensue. Compensatory mechanisms to reduce the hypertension secondary to parasympathetic activity are used above the level of the lesion, hence patients experience sweating, nasal congestion, and flushing. ${ }^{17}$ As well as the mechanisms of spinal reorganisation, other factors have been investigated and may contribute to the pathophysiology. One theory is that after SCI there is an increased responsiveness of vasculature to adrenergic agonists. This has been shown in a small study that examined the peripheral venous response to norepinephrine (noradrenaline) in tetraplegic patients. ${ }^{18}$ This theory complements the one of synaptic reorganisation. Further studies in rats have implicated the upregulation of dopamine $\beta$-hydroxyalse (an enzyme involved in catecholamine synthesis) and substance $\mathrm{P}$ in the development of these aberrant reflexes. ${ }^{19}$

Clearly the development of $\mathrm{AD}$ after injury is a multifactorial complex issue, and further animal and human studies may give us a better insight into these intricate mechanisms.

\section{SYMPTOMS AND SIGNS OF AD}

The symptoms and signs associated with $\mathrm{AD}$ are mainly explained by the putative mechanisms discussed above. Despite this, the presentation may be very different in individual patients. Essentially symptoms and signs of $\mathrm{AD}$ result from the predominant parasympathetic excitation above the level of injury, and sympathetic excitation below the level of injury. ${ }^{2}$ Variation in the presentation of the disorder makes the definition of $\mathrm{AD}$ as a syndrome difficult. Diagnostic clinical criteria have been suggested

Abbreviations: $A D$, autonomic dysreflexia; $S C l$, spinal cord injury 


\section{Box 1 Common symptoms and signs of AD}

- Headache

- Hypertension (note: comparatively low resting blood pressure in SCl)

- Flushing/blotching of skin above level of injury

- Sweating above level of injury

however, that comprise of an increase in systolic blood pressure by at least $20 \%$, and one of the following: sweating, chills, cutis anserine ("goose flesh"), headache, or flushing. It must however be borne in mind that a SCI patient is likely to have a resting blood pressure lower than that of people without SCI. Other common symptoms include nasal congestion (secondary to vasodilatation), malaise and nause (secondary to parasympathetic/vagal effect), blurring of vision, and increased spasms. ${ }^{17}$ Headache is one of the commonest symptoms of $\mathrm{AD}$, and may result from both vasodilatation and hypertension. Rarely, intracranial hypertension may even initiate seizures, ${ }^{19}$ and, if left untreated, intracranial haemorrhage. ${ }^{1}$ The cardiovascular responses associated with $\mathrm{AD}$ are complex and varaiable. Although it is often suggested that bradycardia is a common finding during an episode, the response again varies between people. While the physiological baraoreceptor response to the abnormal hypertension should be to increase parasympathetic activity, thus reducing heart rate, this is not always the case-tachycardia is not an uncommon finding.

\section{PRECIPTANTS OF AD}

The diagnosis of $\mathrm{AD}$ should immediately alert the practitioner to the presence of a reversible and potentially life threatening underlying cause.

\section{Genitourinary}

One of the commonest precipitants of $\mathrm{AD}$ is bladder distension, which alone can account for up to $85 \%$ of episodes. ${ }^{2-4}$ Bladder distension may result from a number of causes, most of which are easily reversed. Blocked or kinked indwelling urinary catheters are one of the commonest causes; these situations can easily be rectified by flushing the catheter lumen or by repositioning, respectively. Urinary tract infection, common in SCI patients, is another precipitant, and should be treated appropriately. Given the complex urological issues surrounding SCI patients, interventional procedures are common. ${ }^{21}$ Practitioners should therefore be aware of the dangers of the whole range of urological interventions. Catheterisation alone may precipitate $\mathrm{AD}$. Urodynamic studies, ${ }^{22}$ cystoscopy, ${ }^{23}$ and interventional procedures for calculi, such as percutaneous nephrolithotomy ${ }^{24}$ or shock wave lithotripsy ${ }^{25}$ may all lead to an episode of AD. Assisted ejaculation is used in SCI male patients for retrieval of sperms for self or in vitro insemination for conception. This may be performed by either by penile vibratory stimulation, or electroejaculation with rectal stimulators; both of these procedures should be considered as risk factors for $\mathrm{AD}^{26}{ }^{27}$ Reflex erections and sexual activity in itself may also lead to episodes of $\mathrm{AD} .^{2}$ Female patients are also at a higher risk of $\mathrm{AD}$ during pregnancy; studies have additionally highlighted the relative frequency of $\mathrm{AD}$ during the stages of labour, and clearly obstetricians should be alert to this complication. ${ }^{28}$

\section{Gastrointestinal}

The second commonest group of causes of AD in SCI are gastrointestinal problems, including faecal impaction and rectal distension. ${ }^{4}$ Anorectal conditions such as haemorrhoids

\section{Box 2 The main precipitants of AD}

- Urological

- Bladder distension, urinary tract infection, urological procedures (for example, cystoscopy, urodynamics), genital stimulation (including assisted ejaculation)

- Gastrointestinal

- Rectal distension, anorectal conditions, anorectal procedures, acute abdomen

- Musculoskeletal

- Fractures, dislocation, heterotopic ossification

- Others

- Skin problems (for example, ulceration, infection), pregnancy and labour.

and fissures may also be precipitants. In parallel to urological procedures, gastrointestinal surgeons should be alert to the diagnosis of $\mathrm{AD}$ during investigative interventions such as proctoscopy and sigmoidoscopy. ${ }^{29} \mathrm{AD}$ can occur despite the use of topical anaesthesia in these circumstances. General surgical conditions of the abdominal organs, such as appendicitis, gastro-oesophageal reflux, and peptic ulceration should also be considered where no other obvious cause exists.

\section{Musculoskeletal}

The combination of skeletal instability and disuse osteoporosis in SCI predisposes patients to fractures. Such fractures (particular spinal) may also be the underlying cause of $\mathrm{AD}$ in patients. ${ }^{30}{ }^{31}$ In addition, dislocation of the hip (which may be occult) can also lead to $\mathrm{AD} .^{32}$ Another complication of SCI is heterotopic ossification, which has also been linked to the onset of $\mathrm{AD}$.

\section{Others}

It must be considered that AD could be related to any noxious stimulus below the level of injury. Thus common problems of skin ulceration and breakdown, or even comparatively minor conditions such as ingrowing toenails should be sought as a cause for the condition. ${ }^{2}$

\section{PREVENTION OF AD}

Perhaps the most important aspect of the management of $\mathrm{AD}$ is the prevention. Structured patient education should be provided during the initial period of rehabilitation, and readily available support thereafter. Equally healthcare professionals of all disciplines should be aware of the potential problems in susceptible people. As the main causes of $\mathrm{AD}$ are related to the urinary tract, avoidance of these complications has become a high priority in the prevention of AD. In addition, careful management of the urinary tract in SCI prevents renal deterioration. Patients with cervical or thoracic SCI commonly have uninhibited detrusor contractions, termed neurogenic detrusor overactivity, and detrusorsphincter dysynnergia. ${ }^{21}$ These combined, result in high residual volumes, urinary tract infections, vesico-ureteric reflux, calculi formation, and ultimately renal scarring and impairment. The goals of urinary tract management in SCI are firstly to ensure low pressure filling of the bladder (usually by means of anticholinergic drugs), and secondly to permit low pressure effective emptying (usually by means of intermittent catheterisation). Hence simply by managing the urinary tract effectively, complications such as overdistension, infection, and calculi may be prevented in the first 
instance. This regimen may not be appropriate in all patients with $\mathrm{AD}$ because, for example, of problems such as poor upper limb function or intolerance to medication. Under these circumstances, alternative such as division of the external urethral sphincter, ${ }^{33}{ }^{34}$ insertion of urethral stents, ${ }^{35}$ balloon dilatation, or pharmacological agents. These invasive interventions, such as urethral stent insertion, may themselves precipitate $\mathrm{AD} .{ }^{36}$ One further approach that has been useful in the abolition of $\mathrm{AD}$ episodes is the combination of sacral anterior root stimulator and posterior rhizotomy. ${ }^{37}$ This system permits low pressure filling and on demand emptying in patients implanted with the device. Other potential causes of $\mathrm{AD}$ include problems such as rectal distension, or skin ulceration. Clearly, strategies aimed at bowel care, and the avoidance of skin damage, will contribute towards preventing an episode of $\mathrm{AD}$.

\section{THE PHARMACOLOGICAL PROPHYLAXIS OF AD}

As discussed above, the diagnosis of recurrent AD should prompt the clinician to search for an underlying cause. With this in mind, there are some data suggesting that $\alpha$ adrenoceptor blockers such as terazosin ${ }^{38} 39$ or prazosin $^{40}$ may be beneficial in the prophylaxis of AD. For SCI patients undergoing surgery, careful consideration of anaesthetic should be observed, and general or spinal anaesthetic may be appropriate in $\mathrm{AD}$ susceptible people. ${ }^{41}$ Whether to provide prophylaxis during more minor procedures is again a contentious issue. For example, $\mathrm{AD}$ complications during electro-ejaculation may be reduced by nifedipine pre-treatment, ${ }^{27}$ yet local anaesthetic jelly may not have such an effect during ano-rectal procedures. ${ }^{29}$

\section{TREATMENT OF ACUTE AD}

Despite $\mathrm{AD}$ being a potentially life threatening event, the management principles of AD remain comparatively straightforward. Early recognition of $\mathrm{AD}$ is important; many patients will be familiar with the initial symptoms of headache, flushing, and sweating, however patients nearer to the acute phase of SCI will be less aware. Unless the situation is easily resolved, it will require at least two people to manage the condition. It may be appropriate for patients who are susceptible to $\mathrm{AD}$ to carry emergency medical cards giving a short summary of causes and treatment, which may assist medical practitioners in the acute management of the condition. The first step of treatment, regardless of the cause, is to sit the patient upright, thus producing an orthostatic decrease in blood pressure. Restrictive clothing such as tight belts should be removed, and blood pressure closely monitored. Once these initial steps have been taken, a search for a reversible precipitant should be sought. If the patient has an indwelling catheter in situ, the drainage bag and catheter should be inspected. If the catheter is blocked, and does not flush it should be changed with the aid of local anaesthetic containing lubricant. If the patient does not have an indwelling catheter in place, for example if they use a regimen of intermittent catheterisation, the bladder should be palpated and, if distended, a urethral catheter passed. If

\section{Box 3 Treatment steps in AD}

- Initial measures (for example, empty bladder, remove faecal mass)-get assistance

- Sublingual nifedipine

- Consider intravenous agent, for example, hydralazine or diazoxide

- Continue searching for underlying cause

\section{Key references}

- Shergill IS, Arya M, Hamid R, et al. The importance of autonomic dysreflexia to the urologist. BJU Int 2004;93:923-6.

- Blackmer J. Rehabilitation medicine: 1. Autonomic dysreflexia. Can Med Assoc J 2003;169:931-5.

- Karlsson AK. Autonomic dysreflexia. Spinal Cord 1999;37:383-91.

- Hambly PR, Martin B. Anaesthesia for chronic spinal cord lesions. Anaesthesia 1998;53:273-89.

- Vaidyanathan S, Soni BM, Sett P, et al. Pathophysiology of autonomic dysreflexia: long-term treatment with terazosin in adult and paediatric spinal cord injury patients manifesting recurrent dysreflexic episodes. Spinal Cord 1998;36:761-70.

the above steps do no resolve the issue, and the patient remains hypertensive and symptomatic, then the rectum should be examined and emptied by gentle insertion of a gloved finger, lubricated in anaesthetic jelly. These steps will resolve most cases. If neither the bladder nor the bowels seem to be the source of the problem, then alternative triggers such as skin ulceration or musculoskeletal disturbance should be sought. This should not preclude the course of emergency treatment, however. Pharmacological treatment of acute AD remains a somewhat contentious issue, and there is a clear lack of randomised controlled data on its role. One of the most commonly used oral hypotensive agents is the calcium antagonist nifedipine. ${ }^{17}{ }^{42} 43$ In our institution this is given sublingually, however others use a "bite and swallow" technique. ${ }^{17}$ Alternative treatments include sublingual or topical nitrates, which should be avoided in those patients taking sildenafil (Viagra). Emerging agents used in acute episodes include sublingual captopril. ${ }^{44}$ Other useful drugs include hydralazine or diazoxide, which are given intravenously.

\section{MULTIPLE CHOICE QUESTIONS (TRUE (T)/FALSE (F); ANSWERS AT END OF REFERENCES)}

(1) Epidemiology of $\mathrm{AD}$ :

(A) Patients with lesions below the level of T6 commonly have symptoms.

(B) $\mathrm{AD}$ only occurs in patients with traumatic spinal cord injury.

(C) Patients with incomplete spinal cord injury can be affected.

(D) Tetraplegics are rarely affected.

(2) Common signs and symptoms of AD include:

(A) Nasal congestion

(B) Hypertension

(C) Tachycardia

(D) Skin flushing above the level of the lesion

(3) Patholphysiology of AD:

(A) $\mathrm{AD}$ is caused by reduced reflex activity after synaptic re-organisation.

(B) Autonomic imbalance leads to splanchnic vasoconstriction.

(C) Parasympathetic activity increases above the lesion.

(D) Goosebumps can be found below the level of the lesion. 


\section{(4) Management}

(A) The first stage of treatment is oral nifedipine.

(B) Lying down eases the symptoms of AD.

(C) $150 \mathrm{~mm} \mathrm{Hg}$ systolic blood pressure is normal in patients with SCI.

(D) Radiographs have no place in the management of $\mathrm{AD}$.

(5) Management

(A) Death may occur due to $\mathrm{AD}$.

(B) Terazosin can be used as a longer term treatment of AD.

(C) Good bowel care may reduce the incidence of AD.

(D) Spinal anaesthesia is contraindicated in SCI.

\section{Authors' affiliations}

J Bycroft, Institute of Urology, UCL, London, UK

I S Shergill, Institute of Urology, UCL, London, UK and Department of Urology, Princess Alexandra Hospital, Harlow, UK

E A L Choong, Department of Gastrointestinal Surgery, St Marks Hospital, Harrow, UK

N Arya, Department of Accident and Emergency, Leicester Royal Infirmary, Leicester, UK

P J R Shah, Institute of Urology, UCL, London, UK, and Royal National Orthopaedic Hospital, Stanmore, UK

Funding: none.

Conflicts of interest: none declared.

\section{REFERENCES}

1 Eltorai I, Kim R, Vulpe M, et al. Fatal cerebral hemorrhage due to autonomic dysreflexia in a tetraplegic patient: case report and review. Paraplegia 1992;30:355-60

2 Shergill IS, Arya $M$, Hamid R, et al. The importance of autonomic dysreflexia to the urologist. BJU Int 2004;93:923-6.

3 Karlsson AK. Autonomic dysreflexia. Spinal Cord 1999:37:383-391.

4 Lindan $\mathbf{R}$, Joiner $E$, Freehafer $A A$, et al. Incidence and clinical features of autonomic dysreflexia in patients with spinal cord injury. Paraplegia 1980;18:285-92

5 Eltorai IM, Wong DH, Lacerna $M$, et al. Surgical aspects of autonomic dysreflexia. J Spinal Cord Med 1997;20:361-4.

6 Moeller BA Jr. Scheinberg D. Autonomic dysreflexia in injuries below the sixth thoracic segment. JAMA 1973;224:1295.

7 Kewalramani LS. Autonomic dysreflexia in traumatic myelopathy. Am J Phys Med 1980;59:1-21.

8 Furlan JC, Fehlings MG, Halliday W, et al. Autonomic dysreflexia associated with intramedullary astrocytoma of the spinal cord. Lancet Oncol 2003;4:574-5.

9 Finestone HM, Teasell RW. Autonomic dysreflexia after brainstem tumor resection. A case report. Am J Phys Med Rehabil 1993;72:395-7.

10 Bateman AM, Goldish GD. Autonomic dysreflexia in multiple sclerosis. J Spinal Cord Med 2002;25:40-2.

11 Wright KC, Agre JC, Wilson BC, et al. Autonomic dysreflexia in a paraplegic man with catecholamine-secreting neuroblastoma. Arch Phys Med Rehabil 1986;67:566-7

12 Armenti-Kapros B, Nambiar PK, Lippman HR, et al. An unusual cause of autonomic dysreflexia: pheochromocytoma in an individual with tetraplegia. J Spinal Cord Med 2003;26:172-5.

13 Krassioukov AV, Furlan JC, Fehlings MG. Autonomic dysreflexia in acute spinal cord injury: an under-recognized clinical entity. J Neurotrauma 2003;20:707-16.

14 Krassioukov AV, Weaver LC. Morphological changes in sympathetic preganglionic neurons after spinal cord injury in rats. Neuroscience 1996;70:211-25.

15 Krassioukov AV, Johns DG, Schramm LP. Sensitivity of sympathetically correlated spinal interneurons, renal sympathetic nerve activity, and arterial pressure to somatic and visceral stimuli after chronic spinal injury. J Neurotrauma 2002;19:1521-9.

16 Mathias CJ, Frankel HL. The cardiovascular system in tetralegia and paraplegia. In: Vinken PJ, Bruyn GW, Klawans HL, et al, eds. Handbook of clinical neurology, Vol 61. Spinal cord trauna. Amsterdam: Elsevier, 1992:434-56.

17 Blackmer J. Rehabilitation medicine: 1. Autonomic dysreflexia. Can Med Assoc J 2003;169:931-5.
18 Arnold JM, Feng QP, Delaney GA, et al. Autonomic dysreflexia in tetraplegic patients: evidence for alpha-adrenoceptor hyper-responsiveness. Clin Auton Res 1995;5:267-70.

19 Cassam AK, Llewellyn-Smith IJ, Weaver LC. Catecholamine enzymes and neuropeptides are expressed in fibres and somata in the intermediate gray matter in chronic spinal rats. Neuroscience 1997;78:829-41.

20 Kursh ED, Freehafer A, Persky L. Complications of autonomic dysreflexia. $J$ Urol 1977;1 18:70-2.

21 Bycroft JA, Hamid R, Shah J, et al. Management of the neuropathic bladder. Hosp Med 2003:64:468-72

22 Perkash I. Autonomic dysreflexia and detrusor-sphincter dyssynergia in spinal cord injury patients. J Spinal Cord Med 1997;20:365-70.

23 Snow JC, Sideropoulos HP, Kripke BJ, et al. Autonomic hyperreflexia during cystoscopy in patients with high spinal cord injuries. Paraplegia 1978;15:327-32

24 Chang CP, Chen MT, Chang LS. Autonomic hyperreflexia in spinal cord injury patient during percutaneous nephrolithotomy for renal stone: a case report. $J$ Urol 1991;146:1601-2.

25 Kabalin JN, Lennon S, Gill HS, et al. Incidence and management of autonomic dysreflexia and other intraoperative problems encountered in spinal cord injury patients undergoing extracorporeal shock wave lithotripsy without anesthesia on a second generation lithotriptor. J Urol 1993;149:1064-7.

26 Szasz G, Carpenter C. Clinical observations in vibratory stimulation of the penis of men with spinal cord injury. Arch Sex Behav 1989;18:461-74.

27 Steinberger RE, Ohl DA, Bennett CJ, et al. Nifedipine pretreatment for autonomic dysreflexia during electroejaculation. Urology 1990;36:228-31.

28 McGregor JA, Meeuwsen J. Autonomic hyperreflexia: a mortal danger for spinal cord-damaged women in labor. Am J Obstet Gynecol $1985 ; 151: 330-3$

29 Cosman BC, Vu T, Plowman BK. Topical lidocaine does not limit autonomic dysreflexia during anorectal procedures in spinal cord injury: a prospective, double-blind study. Int J Colorectal Dis 2002;17:104-8

30 Soni BM, Oo T, Vaidyanathan S, et al. Complications of sacral anterior root stimulator implantation in a cervical spinal cord injury patient: increased spasms requiring intrathecal baclofen therapy followed by delayed fracture of lumbar spine leading to intractable spasms compelling disuse of the sacral anterior root stimulator. Spinal Cord 2004;42:136-8.

31 Beard JP, Wade WH, Barber DB. Sacral insufficiency stress fracture as etiology of positional autonomic dysreflexia: case report. Paraplegia 1996;34:173-5.

32 Graham GP, Dent CM, Evans PD, et al. Recurrent dislocation of the hip in adult paraplegics. Paraplegia 1992;30:587-91.

33 Barton $\mathrm{CH}$, Khonsari F, Vaziri ND, et al. The effect of modified transurethral sphincterotomy on autonomic dysreflexia. J Urol 1986;135:83-5.

34 Ricottone AR, Pranikoff K, Steinmetz JR, et al. Long-term follow-up of sphincterotomy in the treatment of autonomic dysreflexia. Neurourol Urodyn 1995; 14:43-6.

35 Chancellor MB, Rivas DA, Abdill CK, et al. Prospective comparison of external sphincter balloon dilatation and prosthesis placement with external sphincterotomy in spinal cord injured men. Arch Phys Med Rehabil 1994; 75:297-305.

36 Hamid R, Arya M, Wood S, et al. The use of the Memokath stent in the treatment of detrusor sphincter dyssynergia in spinal cord injury patients: a single-centre seven-year experience. Eur Urol 2003;43:539-43.

37 Van Kerrebroeck EV, van der Aa HE, Bosch JL, et al. Sacral rhizotomies and electrical bladder stimulation in spinal cord injury. Part I: Clinical and urodynamic analysis. Dutch Study Group on Sacral Anterior Root Stimulation. Eur Urol 1997;31:263-71

38 Chancellor MB, Erhard MJ, Hirsch $\mathrm{IH}$, et al. Prospective evaluation of terazosin for the treatment of autonomic dysreflexia. J Urol 1994;151:111-13.

39 Vaidyanathan S, Soni BM, Sett P, Watt JW, et al. Pathophysiology of autonomic dysreflexia: long-term treatment with terazosin in adult and paediatric spinal cord injury patients manifesting recurrent dysreflexic episodes. Spinal Cord 1998;36:761-70.

40 Krum H, Louis WJ, Brown DJ, et al. A study of the alpha-1 adrenoceptor blocker prazosin in the prophylactic management of autonomic dysreflexia in high spinal cord injury patients. Clin Auton Res 1992;2:83-8.

41 Hambly PR, Martin B. Anaesthesia for chronic spinal cord lesions. Anaesthesia 1998:53:273-89.

42 Braddom RL, Rocco JF. Autonomic dysreflexia. A survey of current treatment. Am J Phys Med Rehabil 1991;70:234-41.

43 Lindan R, Leffler EJ, Kedia KR. A comparison of the efficacy of an alpha-Iadrenergic blocker in the slow calcium channel blocker in the control of autonomic dysreflexia. Paraplegia 1985;23:34-8.

44 Esmail Z, Shalansky KF, Sunderii R, et al. Evaluation of captopril for the management of hypertension in autonomic dysreflexia: a pilot study. Arch Phys Med Rehabil 2002;83:604-8.

\section{ANSWERS}

1.(A) F, (B) F, (C) T, (D) F, 2. (A) T, (B) T, (C) F, (D) T; 3. (A)

$\mathrm{F}$ (B) T, (C) T, (D) T; 4. (All false); 5. (A) T, (B) T, (C) T, (D) 